\title{
Prospective, Paired Crossover Comparison of the in vitro Quality of Red Blood Cells Collected by the Automate for Blood Collection Device or by a Conventional Method
}

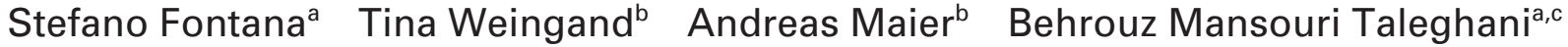 \\ ${ }^{a}$ Blutspendedienst SRK Bern AG, Bern, \\ ${ }^{\mathrm{b}}$ Regionaler Blutspendedienst Zentralschweiz, Luzern, \\ c Universitätsklinik für Hämatologie und Hämatologisches Zentrallabor, Inselspital, Universitätsspital Bern und Universität Bern, \\ Switzerland
}

\section{Key Words}

Whole blood donation · Citrate shock · Red blood cell storage quality

\section{Summary}

Background: The prevention of the citrate shock should improve the quality of red blood cells (RBCs). We compared a conventional whole blood donation method (CONV) with a 'Automate for Blood Collection' (ABC), enabling a metered addition of anticoagulant and hence a correct and constant RBC-to-anticoagulant ratio throughout donation. We evaluated the performance of the $A B C$ device and the storage quality of RBC units. Material and Methods: The study was designed as prospective, paired crossover study with two groups of 20 donors donating first with the ABC or CONV and switching to the alternative method after 12 weeks. We measured the processing data of donations and the storage quality of RBCs on days 1, 28, and 42. Results: $A B C$ whole blood donations showed a slightly higher volume before and after filtration. $\mathrm{ABC}$-derived $\mathrm{RBC}$ units revealed higher values for haematocrit, mean cellular volume, potassium and lower values for mean corpuscular haemoglobin concentration and sodium until day 42. They further showed faster glucose consumption and lactate production until day 28. Conclusion: The ABC device is suitable for whole blood collection. The quality of the obtained RBCs is comparable to that of CONV. Avoiding the citrate shock by the described method did not improve the investigated RBC storage quality parameters.

\section{KARGER}

Fax +497614520714

Information@Karger.de

www.karger.com (c) 2009 S. Karger GmbH, Freiburg

Accessible online at:

www.karger.com/tmh

\author{
Schlüsselwörter \\ Vollblutspende · Zitratschock · Lagerungsqualität von \\ Erythrozytenkonzentraten
}

\section{Zusammenfassung}

Hintergrund: Die Lagerungsqualität von Erythrozytenkonzentraten (EK) sollte sich durch Vermeidung des Zitratschocks verbessern. Wir haben ein konventionelles Vollblutentnahmesystem (CONV) mit dem "Automate for Blood Collection" ( $A B C)$ verglichen. Beim $A B C$-System wird das Antikoagulans dem Vollblut kontinuierlich und im richtigen Verhältnis zugefügt. Wir haben die Funktionalität des ABC-Systems geprüft und die Lagerungsqualität der EK verglichen. Material und Methoden: Die vorliegende Untersuchung wurde als prospektive, gepaarte Crossover-Studie mit 2 Gruppen von je 20 Spendern geplant. Die erste Spende erfolgte entweder unter Einsatz des ABC- oder CONV-Systems, die zweite 12 Wochen später mittels der Alternativmethode. Wir erfassten die Spende- und Herstellungsdaten und untersuchten die Lagerungsqualität der EK an den Tagen 1, 28 und 42. Ergebnisse: Die ABC-Vollblutspenden zeigten vor und nach Filtration ein geringfügig höheres Volumen. Die resultierenden EK wiesen bis zum Tag 42 höhere Werte für Hämatokrit, mittleres Zellvolumen und Kalium auf sowie niedrigere Werte für die mittlere Hämoglobinkonzentration im Einzelerythrozyten und Natrium. Die ABC-EK zeichneten sich durch einen höheren Glukoseverbrauch und eine höhere Laktatproduktion bis Tag 28 aus. Schlussfolgerungen: Das ABC-System eignet sich für die Entnahme von Vollblutspenden. Die Qualität der daraus hergestellten EK ist mit derjenigen aus einer CONV vergleichbar. Die Vermeidung des Zitratschocks unter Einsatz der beschriebenen Methode in ihrem aktuellen Entwicklungsstand führt zu keiner Verbesserung der Lagerungsqualität der EK. 


\section{Introduction}

During the conventional donation procedure, whole blood flows by gravitational force in a bag previously filled with a determined volume of anticoagulant solution such as CPD. The targeted ratio of 7:1 between blood and solution is achieved only at the end of the donation. Therefore, the red blood cells (RBCs) are temporarily exposed to a lower $\mathrm{pH}$ due to a higher concentration of anticoagulant. This imbalance is supposed to cause lesions of RBCs already during the collection procedure, as proposed by Gibson et al. [1] more than 50 years ago. This was confirmed by Mayer and co-workers [2,3] measuring 24-hour survival rates in vivo by means of ${ }^{51} \mathrm{Cr}$-stained RBCs. In the following decades the storage quality of RBCs was significantly improved by several measures, including the switch from ACD to CPD and the introduction of agitating balances. Additionally, it has been postulated that a better standardisation of the whole blood-to-anticoagulant ratio may reduce the lesion of collection [4-6].

The 'Automate for Blood Collection' (ABC, MacoPhar$\mathrm{ma}$ ) is a recently developed device for whole blood donation. It comprises a resting single pan balance and a roller pump, constantly adding CPD from a satellite bag into the draw line during the whole blood donation. It prevents a high CPD concentration at the beginning of the donation, adapts the CPD dose to the collected volume, and thus may improve the quality of the stored RBCs [7].

As a result, $\mathrm{ABC}$ is expected to improve the quality of collected RBCs. In the context of a validation study of ABC aiming for its approval for routine use in Switzerland we compared its performance and the in vitro quality of the obtained RBC concentrates with those of a conventional collection method (CONV).

\section{Material and Methods}

\section{Whole Blood Donation}

Collection and processing of all whole blood donations were performed at the same institution. All donors gave informed consent before inclusion in the study. Donor eligibility criteria were in keeping with the regulations of the Blood Transfusion Service of the Swiss Red Cross. 40 regular whole blood donors were assigned to either the ABC procedure $(n=20)$ or the CONV $(n=20)$. After 12 weeks, the alternative method was applied in each donor . Donors were excluded from whole blood donation and from plasma- or plateletpheresis donation procedures in the 3 months before and 6 weeks before the first study donation, respectively. Other donations were also excluded during the time of participation to the study.

During CONV whole blood was collected by gravitational flow in a quadruple-bag donation set (DQE6281LW, LST2 filter; MacoPharma, Tourcoing/Lille, France), pre-filled with $63 \mathrm{ml}$ of CPD anticoagulant and automatically agitated during donation (Biomixer 315, Baxter, Düdingen, Switzerland). The ABC device uses a similar quadruple-bag donation set (DQE9281LW, LST2 filter; MacoPharma). The only differences between the two donation processes are the way and the point of time of adding the CPD. In particular, with ABC the volume of blood withdrawn is continuously recorded by means of a resting (instead of agitating) single-pan balance. During the whole ABC donation, the required anticoagulant solution is added from a satellite bag containing $80 \mathrm{ml} \mathrm{CPD}$ into the draw line using a roller pump. The addition of CPD is continuously adapted to the increase of the registered weight of the drawn whole blood to achieve a constant ratio of 1:7 [7]

For CONV and ABC the obtained whole blood (450 ml) was subsequently leucocyte-filtered. The filtered whole blood was centrifuged for $18 \mathrm{~min}$ and 4,000 RPM (i.e. 5,134 $\times g$ ) at $22^{\circ} \mathrm{C}$ (Heraeus Cryo 8500 / 8000; Heraeus, Lachen, Switzerland) and separated in a RBC concentrate and a plasma unit (Compomat G4;Fresenius, Stans, Switzerland). The obtained $\mathrm{RBC}$ concentrate was stored in $100 \mathrm{ml} \mathrm{SAG}-\mathrm{M}$ at $4 \pm 2{ }^{\circ} \mathrm{C}$. The plasma was frozen and not further investigated in the context of this study.

\section{Quality Control Testing}

Before donation, blood samples were drawn from each donor for a blood count (Medonic CA 620; Boule Medical AB, Stockholm, Sweden). The durations of donation and of filtration, the weight of the whole blood donation before and after filtration and those of the resulting RBC concentrates were documented. The corresponding volumes were calculated assuming a specific weight of whole blood of 1.05 , of RBC concentrate of 1.07, and of CPD of 1.01. Residual white blood cell (WBC) count was performed by flow cytometry (FACSCalibur; Becton Dickinson, Basel, Switzerland) with propidium iodide staining and fluorescence beads (LeucoCOUNT kit; Becton Dickinson), according to the manufacturer's instructions. The RBC concentrates obtained from all 80 donations were analyzed on days 1,28 , and 42 of storage for the following laboratory parameters: complete blood count (ADVIA 120; Bayer Diagnostics GmbH, Munich, Germany), photometric free haemoglobin (HB) (Philips PU 8675VIS; Philips, Zurich, Switzerland), $\mathrm{pH}$ (at $37^{\circ} \mathrm{C}$ ), lactate, glucose, potassium $\left(\mathrm{K}^{+}\right)$and sodium $\left(\mathrm{Na}^{+}\right)$(ABL 700 Radiometer; Radiometer, Copenhagen, Denmark). The rate of haemolysis was calculated with the following formula:

Haemolysis rate $=(100-\mathrm{HC}) \times$ free $\mathrm{HB} /$ total $\mathrm{HB}$

The haematocrit (HC) is expressed in \%, the free and total HB in $\mathrm{g} / \mathrm{l}$.

\section{Statistical Analysis}

All data were analysed with computer software (NCSS, Kaysville, UT, USA). Donation, filtration, and further quality control data were compared with the t-test for paired samples (parametric data) or the Wilcoxon signed-rank test for non-parametric data. In view of multiple parameters compared, a significant difference between groups was assumed by a more restrictive $\mathrm{p}$ value of $<0.01$ in a two-tailed test.

\section{Results}

\section{Donor Characteristics, Donation and Filtration Data}

All 40 enrolled donors completed the study. All resulting 80 donations were evaluable and yielded RBC concentrates meeting current Swiss quality standards. The donor population consisted of 13 females and 27 males and had a mean age of 43 (range 19-65) years. The mean HB values before donation were 155 (129-179) g/l for CONV and 156 (range $133-174) \mathrm{g} / \mathrm{l}$ for $\mathrm{ABC}(\mathrm{p}=0.77)$.

The donation and filtration data are summarised in table 1. We observed a statistically significant, but minimal volume difference between the ABC and CONV products before and after filtration. There was no difference in the loss of volume during the procedures. The smaller standard deviations of the volumes of $\mathrm{ABC}$ collections imply a better standardisation of 
Table 1. Donation and filtration data

\begin{tabular}{|c|c|c|c|c|c|}
\hline \multirow[t]{2}{*}{ Variable } & \multicolumn{2}{|c|}{ CONV } & \multicolumn{2}{|l|}{$\mathrm{ABC}$} & \multirow[t]{2}{*}{$\mathrm{p}$ value } \\
\hline & mean & $\mathrm{SD}$ & mean & SD & \\
\hline Number of donations & 40 & & 40 & & - \\
\hline Duration of donation, min & 6.6 & 1.6 & 6.2 & 1.0 & 0.13 \\
\hline Duration of filtration, min & 35 & 13 & 35 & 7 & 0.92 \\
\hline WBC contamination $\times 10^{6} /$ unit & 0.05 & 0.04 & 0.1 & 0.07 & $<0.001$ \\
\hline $\mathrm{CPD}^{*}, \mathrm{ml}$ & 63.0 & 0 & 65.9 & 2.2 & - \\
\hline Volume before filtration**, $\mathrm{ml}$ & 506 & 10 & 516 & 4 & $<0.001$ \\
\hline Volume after filtration, $\mathrm{ml}$ & 459 & 11 & 466 & 5 & $<0.001$ \\
\hline Volume lost by filtration, $\mathrm{ml}$ & 52 & 8 & 49 & 3 & 0.51 \\
\hline Volume of RBC R** $^{* *}$ & 285 & 17 & 279 & 21 & 0.432 \\
\hline
\end{tabular}

*CPD content of CONV according to the specifications of the manufacturer.

**Including CPD

***Including SAG-M.

the collected volume. The WBC contamination was higher in the products obtained by $\mathrm{ABC}$, but all showed a WBC count well below $10^{6}$ per unit.

\section{Quality Control Data at Days 1, 28, and 42}

The results of the analyses performed during storage at days 1,28 , and 42 are presented in table 2 . They show several small differences between the two collection procedures. Compared to $\mathrm{CONV}$, the RBCs obtained by the ABC system showed a higher $\mathrm{HC}$ and mean corpuscular haemoglobin concentration (MCHC) during the complete storage time as well as an increasing mean cellular volume (MCV) difference until day 42. Electrolyte changes comprise a faster increase of $\mathrm{K}^{+}$and a decrease of $\mathrm{Na}^{+}$. Metabolic changes are characterised by faster glucose consumption, lactate production, and an accelerated but not significant decline of $\mathrm{pH}$ between day 1 and day 28 .

\section{Discussion}

Modern whole blood collecting systems and additive solutions allow for storage of RBC up to 42 or 49 days with acceptable in vivo survival rates $[8,9]$.

However, many adverse changes in stored RBCs may impair the oxygen transport and delivery capacity of the transfused RBCs, like the loss of S-nitrosohaemoglobin [10] or of 2,3-DPG [11]. These alterations are known to occur during processing and storage of RBCs and are related to storage conditions such as temperature, $\mathrm{pH}$, and chemical composition of the environment. Approved quality assessments of $\mathrm{RBCs}$ at the end of their storage duration comprise the HB content, the rate of haemolysis and the residual leucocyte count [12]. For our study we extended these quality control parameters as described above.

The blood collection and conservation systems have been steadily optimised, taking many of these aspects into account.
Some factors may influence the quality of RBCs already during the collection process itself, like an overwhelming concentration of anticoagulant during the first minutes of blood donation or a variable whole blood-to-anticoagulant ratio [4, 5]. During a conventional donation procedure, whole blood flows in a bag previously filled with a prefixed volume of CPD anticoagulant solution. The targeted ratio of 7:1 between blood and solution is achieved only at the end of the donation. Therefore, the RBCs are initially exposed to a high concentration of anticoagulant and an accordingly low $\mathrm{pH}$ for a few minutes. This may result in a 'lesion of collection'. For RBCs being held in ACD for up to $30 \mathrm{~min}$, it has been shown that their in vitro quality and their in vivo 24-hour survival rates are impaired [1-4].

The ABC may improve the quality of collected RBCs by continuously adding a metered volume of CPD from a satellite bag into the draw line during the whole blood donation [6]. Limited data about ABC have been reported since 2003. These were restricted to processing data [13-15] or, if additional quality control analyses of RBCs were performed, were not directly compared with results of already validated systems $[15,16]$. A recently published controlled study focused on quality of RBC concentrates of sickle trait donors, but the number of donations is insufficient to infer on the quality of ABC under normal conditions [17]. We present the first study comparing the $\mathrm{ABC}$ device with an approved standard whole blood collection system, which was otherwise virtually identical and manufactured by the same company. The comparability of the two groups is further guaranteed by the equal predonation $\mathrm{HB}$ values and the crossover design.

When comparing the performance of CONV and $\mathrm{ABC}$ methods for blood donation and processing, both showed identical values for donation and filtration times as well as for loss of volume by filtration. Although the number of residual WBCs in $\mathrm{ABC}$ is higher than in CONV, all products show WBC counts clearly below $10^{6}$ per unit. The higher volume of the $\mathrm{ABC}$ donations, partially due to the slightly higher volume of CPD anticoagulant, persists after filtration. The lower standard deviations additionally indicate a more standardised collection volume with $\mathrm{ABC}$ compared to CONV. This may be the result of continuously weighing a resting instead of an agitating bag. However, this does not result in a higher standardisation of the final products ( $\mathrm{RBC}$ units and plasma), as measured by the standard deviations of the quality control data during storage (table 2).

All quality control parameters meet the current Swiss and European standards. The majority of the haematological and chemical changes observed during storage of RBCs obtained by $\mathrm{ABC}$ or $\mathrm{CONV}$ are comparable. We only observed some minor differences in several parameters. Although the identical centrifugation and separation protocols of $\mathrm{ABC}$ and CONV lead to identical total HB contents in the RBC units, an increase of MCV resulted in an increased $\mathrm{HC}$ and a decreased $\mathrm{MCHC}$ in $\mathrm{ABC}$. The latter has also been reported for RBCs derived from erythroplasmapheresis with a single needle 
Table 2. Quality control data at days 1,28 , and 42

\begin{tabular}{|c|c|c|c|c|c|c|c|c|c|c|c|c|c|c|c|}
\hline \multirow[t]{3}{*}{ Parameter } & \multicolumn{5}{|l|}{ D1 } & \multicolumn{5}{|l|}{ D28 } & \multicolumn{5}{|l|}{ D42 } \\
\hline & \multicolumn{2}{|l|}{ CONV } & \multicolumn{2}{|l|}{$\mathrm{ABC}$} & \multirow[t]{2}{*}{$\mathrm{p}$} & \multicolumn{2}{|l|}{ CONV } & \multicolumn{2}{|l|}{$\mathrm{ABC}$} & \multirow[t]{2}{*}{$\mathrm{p}$} & \multicolumn{2}{|l|}{ CONV } & \multicolumn{2}{|l|}{$\mathrm{ABC}$} & \multirow[t]{2}{*}{$\mathrm{p}$} \\
\hline & mean & $\mathrm{SD}$ & mean & SD & & mean & $\mathrm{SD}$ & mean & SD & & mean & $\mathrm{SD}$ & mean & $\mathrm{SD}$ & \\
\hline $\mathrm{HC}, \%$ & 63.6 & 2.4 & 64.5 & 2.1 & 0.007 & 65.7 & 2.6 & 68.1 & 4.1 & $<0.001$ & 65.5 & 2.6 & 67.2 & 3.5 & $<0.001$ \\
\hline $\mathrm{RBC} \times 10^{12} / 1$ & 6.72 & 0.34 & 6.80 & 0.38 & 0.052 & 6.77 & 0.37 & 6.85 & 0.51 & 0.213 & 6.66 & 0.37 & 6.73 & 0.33 & 0.148 \\
\hline $\mathrm{Hb}, \mathrm{g} / \mathrm{unit}$ & 58.0 & 5.7 & 56.9 & 5.8 & 0.605 & 58.2 & 5.5 & 57.9 & 6.6 & 0.989 & 57.6 & 5.7 & 57.1 & 6.3 & 0.917 \\
\hline MCV, fl & 94.7 & 4.3 & 95.1 & 3.8 & 0.747 & 97.1 & 4.2 & 99.7 & 5.0 & $<0.001$ & 98.4 & 4.5 & 100.0 & 5.1 & $<0.001$ \\
\hline $\mathrm{MCH}, \mathrm{pg}$ & 30.3 & 1.3 & 30.0 & 1.6 & 0.081 & 30.2 & 1.3 & 30.3 & 1.7 & 0.762 & 30.4 & 1.3 & 30.4 & 1.4 & 0.721 \\
\hline MCHC, g/l & 320 & 12 & 316 & 10 & 0.001 & 311 & 7 & 304 & 6 & $<0.001$ & 309 & 7 & 304 & 8 & $<0.001$ \\
\hline $\mathrm{PLT} \times 10^{9} / 1$ & 1.05 & 0.23 & 1.00 & 0.82 & 0.618 & 1.16 & 0.50 & 1.26 & 0.87 & 0.689 & 1.48 & 0.78 & 1.45 & 1.45 & 0.681 \\
\hline Free $\mathrm{Hb}, \mathrm{g} / \mathrm{l}$ & 0.15 & 0.10 & 0.18 & 0.12 & 0.330 & 0.70 & 0.30 & 0.80 & 0.30 & 0.014 & 1.43 & 0.70 & 1.49 & 0.50 & 0.171 \\
\hline Haemolysis, \% & 0.03 & 0.02 & 0.03 & 0.02 & 0.296 & 0.12 & 0.05 & 0.12 & 0.05 & 0.623 & 0.24 & 0.12 & 0.24 & 0.08 & 0.525 \\
\hline $\mathrm{K}^{+}, \mathrm{mmol} / \mathrm{l}$ & 3.13 & 0.44 & 3.14 & 0.48 & 0.984 & 38.5 & 2.8 & 40.1 & 4.1 & 0.003 & 46.7 & 3.2 & 49.3 & 3.5 & $<0.001$ \\
\hline $\mathrm{pH}\left(37^{\circ} \mathrm{C}\right)$ & 6.96 & 0.06 & 6.98 & 0.06 & 0.092 & 6.51 & 0.04 & 6.49 & 0.07 & 0.033 & 6.46 & 0.31 & 6.40 & 0.05 & 0.144 \\
\hline $\mathrm{Na}^{+}, \mathrm{mmol} / \mathrm{l}$ & 140.4 & 0.9 & 140.4 & 1.6 & 0.920 & 109.4 & 3.2 & 107.8 & 4.5 & 0.011 & 101.6 & 2.6 & 100.0 & 3.8 & 0.002 \\
\hline Lactate, $\mathrm{mmol} / \mathrm{l})$ & 5.86 & 1.07 & 5.52 & 1.15 & 0.075 & 26.45 & 2.45 & 28.54 & 4.35 & $<0.001$ & 31.90 & 3.28 & 32.23 & 3.74 & 0.418 \\
\hline Glucose, mmol/l & 26.9 & 1.2 & 27.8 & 1.5 & 0.006 & 16.9 & 1.7 & 16.3 & 1.9 & 0.028 & 13.6 & 2.0 & 13.4 & 2.4 & 0.367 \\
\hline
\end{tabular}

apheresis device [6]. With respect to the discordant course of $\mathrm{K}^{+}$and $\mathrm{Na}^{+}$concentrations, enhanced physical changes in the $\mathrm{RBC}$ membrane collected with $\mathrm{ABC}$ have to be suggested, e.g. by an impaired activity of the Na-K-ATPase. Additionally, we observed higher glucose consumption and corresponding increased lactate concentration between day 1 and 28 in RBCs collected by ABC. These differences were too small to result in significantly different $\mathrm{pH}$ values, and disappeared until day 42. More in-depth in vitro analyses (such as 2,3-DPG, rheological parameters, or even proteomics) and clinical outcome parameters may be included in future studies.

Taken together our results revealed the $\mathrm{ABC}$ device to be suitable for whole blood collection. The quality of the obtained RBCs is comparable to that of products gained by conventional whole blood donation methods and meets the current Swiss and European standards. Avoiding the citrate shock by maintaining a correct and constant whole blood-toanticoagulant ratio during donation with the described method at its current stage of development did not improve the investigated RBC storage quality parameters.

\section{Disclosure}

The authors declared no conflict of interest.

\section{References}

1 Gibson J, Murphy W, Scheitlin W, Rees S: The influence of extracellular factors involved in the collection of blood in ACD on maintenance of red cell viability during refrigerated storage. Am J Clin Pathol 1956;28:569-578.

2 Mayer K, Ley A, D'Amaro J: Impairment of red cell viability by exposure to 'excess' acid-citratedextrose. Blood 1966;28:513-523.

$\checkmark 3$ Mayer K, Dwyer A, Laughlin J: Spleen scanning using ACD-damaged red cells tagged with $\mathrm{Cr} 51$. Eur J Nucl Med 1970;11:455-458.

$\checkmark 4$ Weisbach V, Hunold I, Zimmermann R, Lutter N, Parsch H, Zingsem J, Glaser A, Eckstein R: In vitro characteristics of red blood cell concentrates prepared from under- and overcollected units of whole blood and from a paediatric bag system. Transfus Med 2000;10:23-30.

5 Cober N, Lacasse M, Bart B, Rock G: Effects of different concentrations of anticoagulant on the in vitro characteristics of autologous whole blood Transfusion 2001;41:1606-1609.

6 Matthes G, Tofote U, Krause KP, Pawlow I, Kucera W, Lerche D: Improved red cell quality after erythroplasmapheresis with MCS-3P. J Clin Apher 1994;9: 183-188.
7 Castrillo A, Areal C, Abalo M, Adelantado M, Castro A, Cid J, Eiras A, Flores J, Cabrera J: Evaluation of blood components collected by ABC system. Vox Sang 2007;93:98.

8 Heaton WA, Keegan T, Holme S, Momoda G: Evaluation of 99 mtechnetium/51chromium post-transfusion recovery of red cells stored in saline, adenine, glucose, mannitol for 42 days. Vox Sang 1989;57: $37-42$.

9 Walker WH, Netz M, Gänshirt KH: 49 day storage of erythrocyte concentrates in blood bags with the PAGGS-mannitol solution. Beitr Infusionther 1990;26:55-59.

10 Bennett-Guerrero E, Veldman TH, Doctor A, Telen M J, Ortel TL, Reid TS, Mulherin MA, Zhu H, Buck RD, Califf RM, McMahon TJ: Evolution of adverse changes in stored RBCs. Proc Natl Acad Sci U S A 2007;104:17063-17068.

11 Högman F, Meryman HT: Red blood cells intended for transfusion: quality criteria revisited. Transfusion 2006;46:137-142.

12 Guide to the Preparation, Use and Quality Assurance of Blood Components, 14 ed. Strasbourg, Council of Europe, 2008.
13 Dadiotis L, Kolokytha A, Dimou M, Perdiou A, Alepi C, Spyropoulou P, Igoumenides E, Velidou C, Panagopoulou V, Matsagos SA: Evaluation of an automated blood collection system with standard ratio of anticoagulation and integrated filter for whole blood leucodepletion. Vox Sang 2005; 89(suppl 1):198-199.

14 Parara M, Megalou A, Costourou P, Koutsagianni E, Gerovangeli G, Kapasouri E, Grigoriou S, Savidakis M: Comparison of a routine blood collection to a new automated collection technique (ABC). Vox Sang 2005;89(suppl 1):198.

15 Bigey F, Isola H, Wiesel ML, Cazenave J-P: Whole blood collection with continuous proportional anticoagulation using the MacoPharma ABC automate. Vox Sang 2006;91(suppl 3):312-313.

16 Schooneman F, Huart JJ, Aguettaz D, Delemer N: MacoPharma ABC a new concept to improve the quality of whole blood collections. Vox Sang 2004; 87(suppl 3):57.

17 Bryant B, Bianchi M, Wesley R, Stroncek DF, Leitman SF: Leukoreduction filtration of whole blood units from sickle trait donors: effects of a metered citrate anticoagulant system. Transfusion 2007;47:2233-2241. 